\title{
Formability of Materials with Small Tools in Incremental Forming
}

\author{
Hongyu Wei ${ }^{1}$, G. Hussain ${ }^{2 *}$, X. Shi ${ }^{3}$, B. B. L Isidore ${ }^{4}$, Mohammed Alkahtani ${ }^{5,6}$ and Mustufa Haider Abidi ${ }^{6}$
}

\begin{abstract}
Single point incremental forming (SPIF) is an innovative sheet forming process with a high economic pay-off. The formability in this process can be maximized by executing forming with a tool of specific small radius, regarded as threshold critical radius. Its value has been reported as $2.2 \mathrm{~mm}$ for $1 \mathrm{~mm}$ thick sheet materials. However, with a change in the forming conditions specifically in the sheet thickness and step size, the critical radius is likely to alter due to a change in the bending condition. The main aim of the present study is to undertake this point into account and develop a relatively generic condition. The study is composed of experimental and numerical investigations. The maximum wall angle $\left(\theta_{\max }\right)$ without sheet fracturing is regarded as sheet formability. A number of sheet materials are formed to fracture and the trends correlating formability with normalized radius (i.e., $R / T_{0}$ where $R$ is the tool-radius and $T_{0}$ is the sheet thickness) are drawn. These trends confirm that there is a critical tool-radius $\left(R_{c}\right)$ that maximizes the formability in SPIF. Furthermore, it is found that the critical radius is not fixed rather it shows dependence on the sheet thickness such that $R_{c}=\beta T_{\text {o, }}$ where $\beta$ varies from 2.2 to 3.3 as the thickness increases from $1 \mathrm{~mm}$ to $3 \mathrm{~mm}$. The critical radius, however, remains insensitive to variation in step size ranging from $0.3 \mathrm{~mm}$ to $0.7 \mathrm{~mm}$. This is also observed that the selection of tool with $R<R_{c}$ narrows down the formability window not only on the higher side but also on the lower side. The higher limit, as revealed by the experimental and FEA results, diminishes due to excessive shearing because of in-plane biaxial compression, and the lower limit reduces due to pillowing in the bottom of part. The new tool-radius condition proposed herein study would be helpful in maximizing the formability of materials in SPIF without performing experimental trials.
\end{abstract}

Keywords: Incremental forming, Critical tool-radius, Formability curve, Finite element analysis

\section{Introduction}

Single point incremental forming (SPIF) is an innovative sheet-forming technique economically well suited for low batch production and prototyping. In fact, this process contrary to traditional press forming operations [1] does not employ dedicated set of tooling in order to perform three-dimensional shaping. The blank is held at the periphery in a clamping rig, and a simple sphericalend tool tightened in a spindle of $\mathrm{CNC}$ milling machine follows a predefined path to produce the target shape in a series of loops. These features render SPIF a very

\footnotetext{
*Correspondence: gh_ghumman@hotmail.com

2 Faculty of Mechanical Engineering, GIK Institute of Engineering Sciences

\& Technology, Topi 23460, Pakistan

Full list of author information is available at the end of the article
}

flexible process. The process has demonstrated numerous applications in the automotive, biomedical and aircraft industries $[2,3]$. Though its understanding with growing research has improved in the past years, yet the process is immature to be successfully deployed on industrial scale. The research community is spending a great deal of efforts in order to improve its industrial suitability in terms of applications and sustainability [4-11].

The limit by which a sheet can be formed without fracturing (i.e., formability) has been a matter of concern for every sheet forming process, because this limit has influence on the process window thereby directly affecting the achievable product. The SPIF process offers higher formability than a conventional pressing process [12-14]. The shear, bending and local deformation have been reported as the main factors in this regard [14-17]. Centrino et al. 
[18] have presented a good piece of work on this subject. Isolating the effect of stretching and bending, they found that the localized nature of deformation significantly contributes in raising the formability in SPIF in comparison to conventional forming. Furthermore, tools with smaller radii ( $\mathrm{R}$ as defined in Figure 1 (a)) suppress the neck formation and delay the fracture. The advantage of employing smaller tools on the formability has been also recognized by many other authors [19-24].

However, a small-radius tool does not necessarily raise the sheet formability in SPIF. Excessively small tools can push the process from a regular forming state to an irregular one whereby the forming tool plows the sheet thereby squeezing out the material from the tool/sheet interface and causing a premature failure. This state happens when the tool size is smaller than a critical value. In Ref. [25], this critical value has been proposed as a function of sheet thickness, i.e., $R_{c}=\beta T_{o}$ where the coefficients $\beta$ is 2.2. The proposed critical small radius is believed to maximize the formability in SPIF. This critical condition was developed by employing the sheet material of $1 \mathrm{~mm}$ thickness and step size of $0.2 \mathrm{~mm}$. As bending affects deformation stability in SPIF $[16,18]$, and the

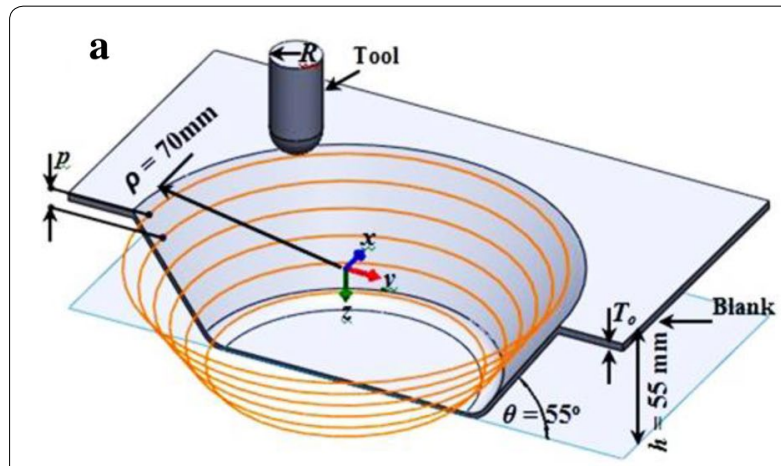

b

b
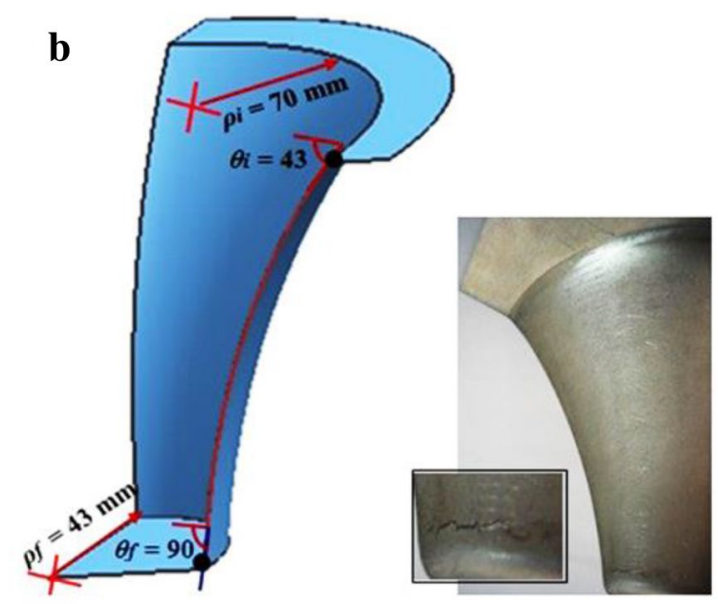

Figure 1 The terminology and test geometries: a Fixed angle frustum of cone, and $\mathbf{b}$ Varying wall angle frustum of cone bending condition alters with the sheet thickness and step size, it is most likely that the formability will vary accordingly thereby affecting the critical small radius consequently. The present study investigates this point in detail with an objective to explore a more generic critical small radius condition as opposed to the specific one proposed in Ref. [25].

To achieve the objective, a set of aluminum and steel sheets with different thicknesses is selected and formed to fracture employing a range of tool radii and two levels of step size. The critical small radius offering the maximum formability is identified in each test. The FEA is conducted to study the strain state and deformation physics under the forming tools, especially small ones. Interestingly, the coefficient in critical radius condition is found to show dependence on the sheet thickness thereby specifying a critical range and further clarifying and correcting the condition reported in the early work [25]. This newly proposed critical small radius condition is relatively generic, applicable under wider forming conditions.

\section{Procedures for Experiments and Finite Element Modeling}

To obtain a generalized condition of critical small radius, the formability tests were performed on five sheet-metals with different conditions (such as annealed, cold worked and T6-tempered) and having different thicknesses ( 0.8 $\mathrm{mm}$ to $3 \mathrm{~mm}$ ) (Table 1). One sheet from each type of material sheet (i.e., one thickness only) was subjected to tensile test on a universal testing machine. The test was performed at a cross head speed of $2 \mathrm{~mm} / \mathrm{min}$ and following the ASTM-E8 standard.

Table 1 Experimental plan

\begin{tabular}{|c|c|c|c|c|}
\hline Material & Condition & $\mathrm{T}_{\mathrm{o}}(\mathrm{mm})$ & $\mathrm{R}(\mathrm{mm})$ & $\begin{array}{l}\text { Tensile area } \\
\text { reduction } \\
(\%)\end{array}$ \\
\hline \multirow{2}{*}{$\begin{array}{l}\text { AA2024 } \\
\text { (Aluminum) }\end{array}$} & \multirow[t]{2}{*}{ T6 } & 0.97 & $1,1.5,2.2,2.5,3.3 .5$ & \multirow[t]{2}{*}{24} \\
\hline & & 1.95 & $1.5,2,2.2,2.5,3,3.5$ & \\
\hline \multirow{2}{*}{$\begin{array}{l}\text { AA2024 } \\
\text { (Aluminum) }\end{array}$} & \multirow[t]{2}{*}{$\mathrm{O}$} & 0.97 & $1,2,2.2,3.5$ & \multirow[t]{2}{*}{41.5} \\
\hline & & 2.95 & $1.5,1.8,2,2.2,2.5,3$ & \\
\hline $\begin{array}{l}\text { DS } \\
\text { (Steel) }\end{array}$ & $\mathrm{O}$ & 0.8 & $1.5,1.8,2,2.5$ & 64 \\
\hline \multirow{3}{*}{$\begin{array}{l}\text { AA1060 } \\
\text { (Aluminum) }\end{array}$} & \multirow[t]{3}{*}{$\mathrm{H} 24$} & 0.9 & $1,1.5,2,2.5,3,3.5$ & \multirow{3}{*}{70.5} \\
\hline & & 1.84 & $\begin{array}{l}1,1.5,2,2.2,2.5 \\
\quad 3,3.5\end{array}$ & \\
\hline & & 2.4 & $\begin{array}{l}1,1.5,1.8,2,2.2 \\
\quad 2.5,3\end{array}$ & \\
\hline \multirow{2}{*}{$\begin{array}{l}\text { AA1060 } \\
\text { (Aluminum) }\end{array}$} & \multirow[t]{2}{*}{$\mathrm{O}$} & 0.9 & $1,1.5,2,2.5,3,3.5$ & \multirow[t]{2}{*}{82} \\
\hline & & 1.84 & $\begin{array}{l}1,1.5,2,2.2,2.5 \\
\quad 3,3.5\end{array}$ & \\
\hline
\end{tabular}


As listed in Table 1, the tensile area reduction (a formability indicator in SPIF [2]) of these materials varied from 24\% (AA2024-T6) to 82\% (AA1060-O). This ensured that the possible effect of properties variation on small radius condition was included in order to realize a generic tool-radius condition. The formability in the present study was defined as the maximum wall-angle that a sheet endures without fracturing (i.e., $\left.\theta_{\text {max }}\right)$, a measure commonly employed in the SPIF literature. The formability was determined employing the VWACF test, proposed in Ref. [26]. This test makes use of a conical frustum whose wall-angle $(\theta$ as defined in Figure 1 (b)) continuously increases with the depth thus inducing corresponding thinning. The sheet finally fractures somewhere between $0^{\circ}$ and $90^{\circ}$ whenever the thinning limit is surpassed, and the wall-angle corresponding to fracture is regarded as $\theta_{\max }$.

The geometry of the test used herein study has been shown in Figure 1 (b). In order to ensure plane-strain condition during forming, the diameters of the frustums (especially the top and bottom diameters) were kept large following the guidelines reported in Ref. [27]. All kinds of tests, including $55^{\circ}$ cones and formability cones, were performed keeping the operating parameters fixed as: feed rate: $3000 \mathrm{~mm} / \mathrm{min}$; spindle speed: 0 $\mathrm{rev} / \mathrm{min}$ and step size: $0.3 \mathrm{~mm}$. In order to examine the effect of step size on material plowing/flow mentioned earlier and hence on the small radius condition, some additional tests were performed employing AA10160$\mathrm{H} 24$ as the test material. The step size in these tests was increased from $0.3 \mathrm{~mm}$ to $0.7 \mathrm{~mm}$. In order to provide statistical means to the data, the tests were repeated twice.

The ABAQUS computing package was used for finite element modeling. The frustum of cone with the fixed angle of $55^{\circ}$ was simulated using explicit modeling technique because this modeling method reduces computational time and provides results with reasonable accuracy [28]. The commercial $\mathrm{Al}$ (1 mm thick) obeying the following hardening law was used as the modeling material:

$$
\bar{\sigma}=\bar{\varepsilon}^{0.2}
$$

where $\tilde{\sigma}$ and $\bar{\varepsilon}$ are the effective stress and effective strain, respectively. Both the sheet and forming tool were discretized using C3D8R brick elements $(0.5 \mathrm{~mm} \times 0.5 \mathrm{~mm} \times$ $1 \mathrm{~mm})$. The nature of contact at the tool/sheet interface was set as hard, i.e., the tool was not allowed to penetrate into the sheet. The friction coefficient at the contacting interface, which was acquired from the pin-on-disc test, was defined as 0.05 . The simulations were done employing three different normalized tool radii ' $R$, i.e., 1.1 (lowest), 2.2 and 3.9 (highest).

\section{Experimental and Numerical Simulation Results}

Figure $2(\mathrm{a}-\mathrm{d})$ presents the formability (i.e., $\left.\theta_{\max }\right)$ as a function of normalized tool-radius ' $R$ for four different sheet materials. The normalized radius was used because it determines the mechanisms (bending and shear) that affect the failure [18] and hence serves as a meaningful formability determinant. Contrary to one thickness in [25], the formability is shown for sheets of various thicknesses. As can be observed, formability in each of the sheet materials increases to the maximum value followed by a gradual decrease as the normalized radius ' $R$ decreases. Thus, the formability follows an inverse $\mathrm{V}$-type trend over the range of ' $R$. There is one maximum value of $\theta_{\max }$ in each formability curve and this occurs against a specific tool-radius which can be termed as critical small radius and can be denoted as ' $R_{c}$.

To the right of formability diagram/curve, the formability trend is in agreement with the previous studies [19-24] which attribute this trend to increase in the size of deformation zone and damage when the tool-radius increases. To the left of formability curve, however, the trend is uncommon and similar to what observed in Ref. [25] for $1 \mathrm{~mm}$ thick sheets. This peculiar trend can be reasoned to corresponding increase in material plowing and damage with a decrease in the tool-radius [25].

This is to observe from Figure 2(a-d) that the formability in SPIF (i.e., $\theta_{\max }$ ) in agreement with the literature [19, 20] shows dependence on the sheet thickness. However, interestingly, there are some examples in which a thin sheet offers higher formability than a thick sheet, despite forming was performed under the same conditions and using a constant tool-radius ' $R$. This trend is more pronounced in annealed sheets: say in 2024-O against ' $R$ of 2 and in 1060-O against ' $R$ of 1.1. This might be attributed to a reason that thin sheets during SPIF experience greater elastic bending and thus reduced bending strains than the thick sheets. Besides affecting the formability, sheet thickness also influences the maximum achievable value of $\theta_{\max }$ (i.e., ' $\theta_{\max }$ ) over the investigated range of tool-radius ' $R$. For example, the value of ' $\theta_{\max }$ of AA2024T6, increases from $52^{\circ}$ to $53.5^{\circ}$ as the thickness of sheet increases from $1 \mathrm{~mm}$ to $2 \mathrm{~mm}$. A similar result is shown by AA10160-H24. However, for annealed materials (such as AA1060-O and AA2024-O), an increase in the sheet thickness does not significantly affect the value of ' $\theta_{\max }$. In addition to operating parameters and material thickness, the formability also depends on the material properties [13]. Therefore, the above variation in ' $\theta_{\max }$ with sheet thickness might have appeared due to corresponding variation in the properties.

As observable from Figure 2(a-d), the critical value of normalized radius ' $R_{c}$ offering the maximum formability ' $\theta_{\max }$ consistent with Ref. [25] is about 2.2 (with a slight 


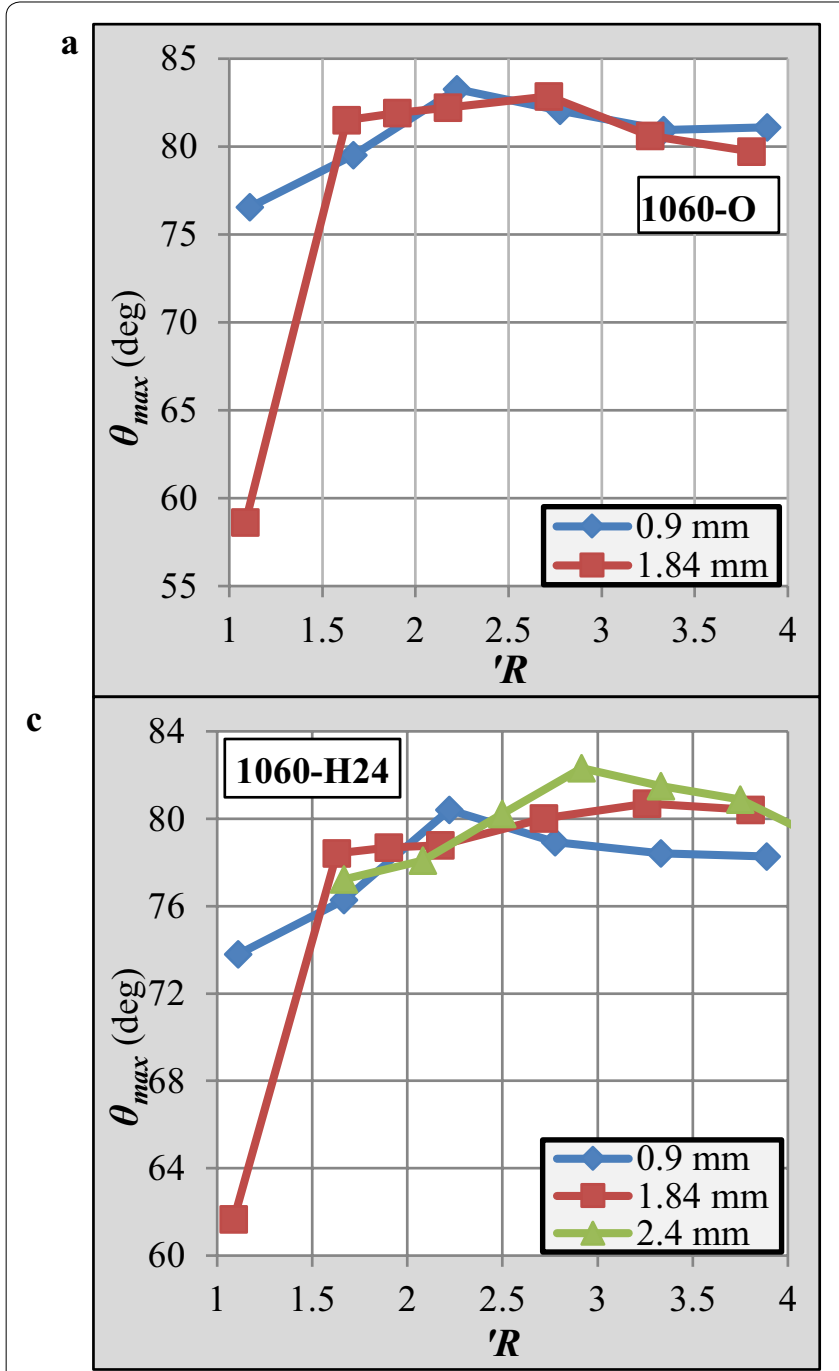

b

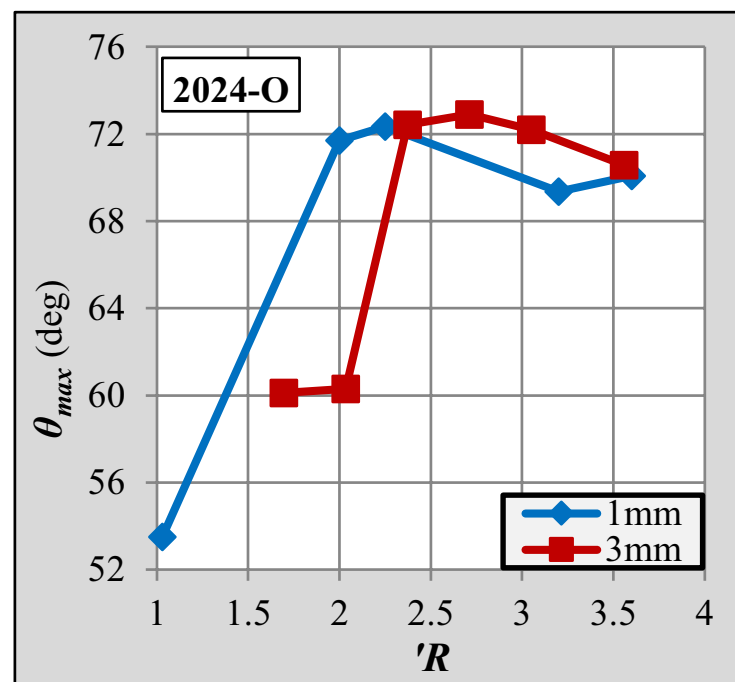

d

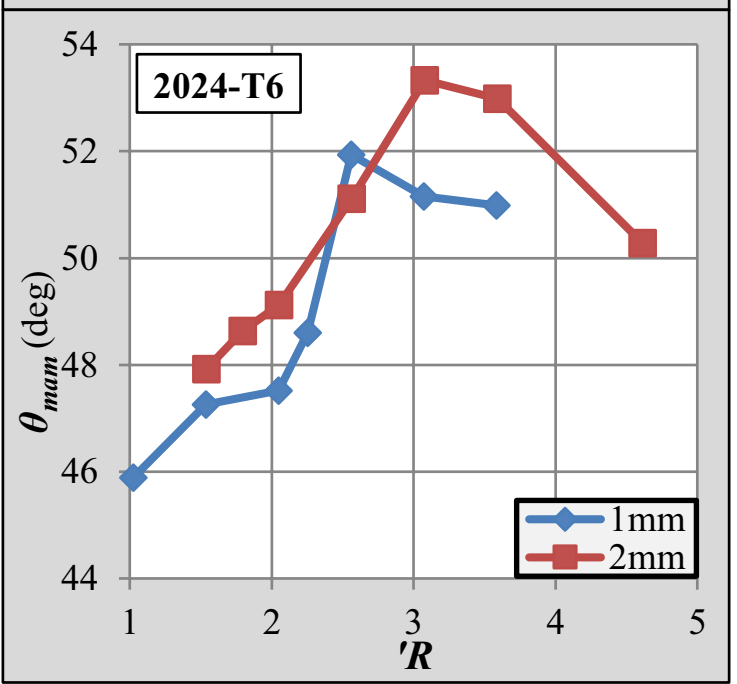

Figure 2 Formability curves of various at varying thickness: a 1060-O, b 2024-O, c 1060-H24, and d 2024-T6: avg dev in the results ranged from $0.03 \%$ to $0.12 \%$

variation) for $1 \mathrm{~mm}$ thick sheet metals. However, its value increases as the sheet thickness increases, e.g., from 2.2 to 3.3 as the thickness of AA2024-T6 increases from $0.9 \mathrm{~mm}$ to $2 \mathrm{~mm}$. Overall, ' $R_{c}$ ranges from 2.2 to 3.3 or alternatively $R_{c}$ ranges from $2.2 T_{o}$ to $3.3 T_{o}$. This finding, as expected, reveals that the coefficient $\beta$ of the threshold radius condition in SPIF is not fixed rather its value is dependent on the sheet thickness. The reason of this interesting finding can be explained by the bend severity (or bending strain) experienced by the sheet during SPIF. Theoretically, the bend severity and bending strain are determined by the parameter $R / T_{o}$. However, during forming with a constant tool-radius, the thick sheet experiences lower elastic bending than the thin sheet thus correspondingly enduring higher bending strains and material plowing leading to early failure. Therefore, a thicker sheet realizes the maximum formability with a tool of slightly larger radius because the bending strains and plowing reduce accordingly thereby overcoming the irregular state of forming. This is to notice from Figure 2 that the $1.84 \mathrm{~mm}$ thick AA1060-H24 sheet has a higher value of ' $R_{c}$ (3.3) than the $1.84 \mathrm{~mm}$ thick AA1060-O sheet (2.7). This means that besides thickness the condition of the material also affects the value of ' $R_{c}$ when thicker sheets are processed in SPIF.

Figure 3 presents the formability curves for two different step sizes (i.e., $0.3 \mathrm{~mm}$ and $0.7 \mathrm{~mm}$ ). As can be seen, a variation in the step size does not cause any visible influence on the shape of formability curve. More important, there is no noticeable change in the value of ' $R_{c}$ due to 


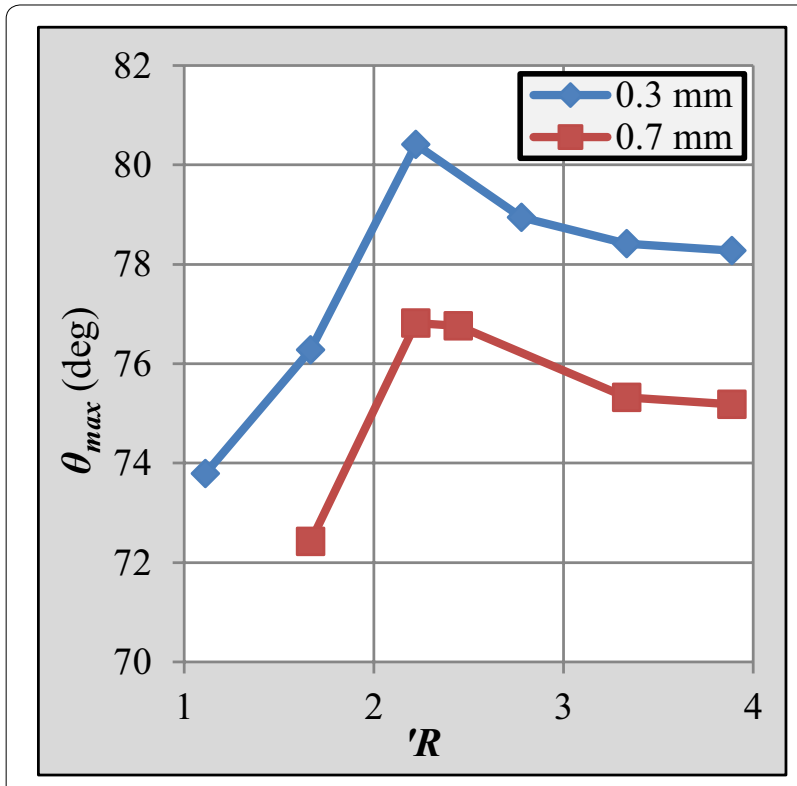

Figure 3 Formability curves at varying step size

increase in the step size which follows that the step size is not a very influential parameter for ' $R_{c}$, at least in the investigated range. Therefore, the following small radius condition to maximize the formability in SPIF can be proposed:

$$
{ }^{\prime} R_{c}=\beta .
$$

Alternatively, Eq. (2) can be written as:

$$
R_{c}=\beta T_{o},
$$

where the coefficient $\beta$ varies from 2.2 to 3.3 .

Figure 4 presents the distribution of in-plane $X$ - and $Y$-strains on the inner surface, as defined in the figure, for three different settings of ' $R$ : $X$ is the direction of tool travel and $Y$ is the transverse direction. From the strain values, it is evident that the sheet in the $X$-direction experiences compression which decreases (in terms of magnitude) as the value of ' $R$ increases from 1.1 to 3.9. In the $Y$-direction, the sheet encounters compression only when processing is done with very small tool (i.e., for ' $R<2.2$ ). Moreover, this is to mention that the compression prevails only on the inner surface while the outer surface for any of the opted tools (i.e., for ' $R$ ranging from 1.1 to 3.9) was observed to experience tension due to stretching. Further, the nature of strain on the inner surface gradually shifts from compression to tension as the value of ' $R$ increases from 1.1 onwards. Considering the reduced formability and in-plane compression observed for ' $R_{c}<$ 2.2 , it can be said that the in-plane biaxial compression is not conducive for improving formability in SPIF.

In fact, this condition on one hand causes material plowing and on the other hand induces intensive contact pressure (i.e., from $-6 \times 10^{7} \mathrm{~Pa}$ to $-3.27 \times 10^{7} \mathrm{~Pa}$ as $R$ increases from 1.1 to 3.9 , see Figure 5). Consequently, material plowing, in terms of height of squeezed material as depicted in Figure 6(a), increases with each increment of forming loop due to corresponding increase in compression at the tool/sheet interface: see $\mathrm{X}$ and $\mathrm{Y}$ stress

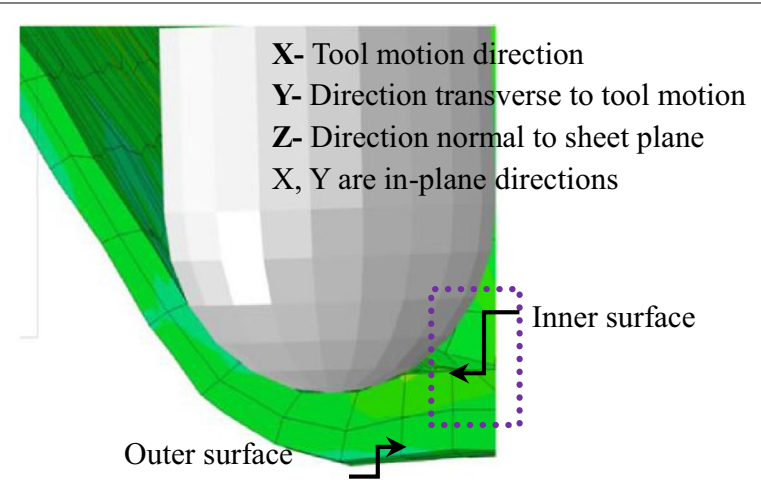

\begin{tabular}{ccc}
\hline $\boldsymbol{R}$ & $\begin{array}{c}\text { Strain components on the inner surface of sheet } \\
\text { plane against the location shown in the half section }\end{array}$ \\
\hline & X-strain & Y-strain \\
1.1 & -0.03 & -0.045 \\
2.2 & -0.03 & 0.0 \\
3.9 & -0.01 & +0.0015 \\
\hline
\end{tabular}

Figure 4 Strain state of sheet in front of tool 


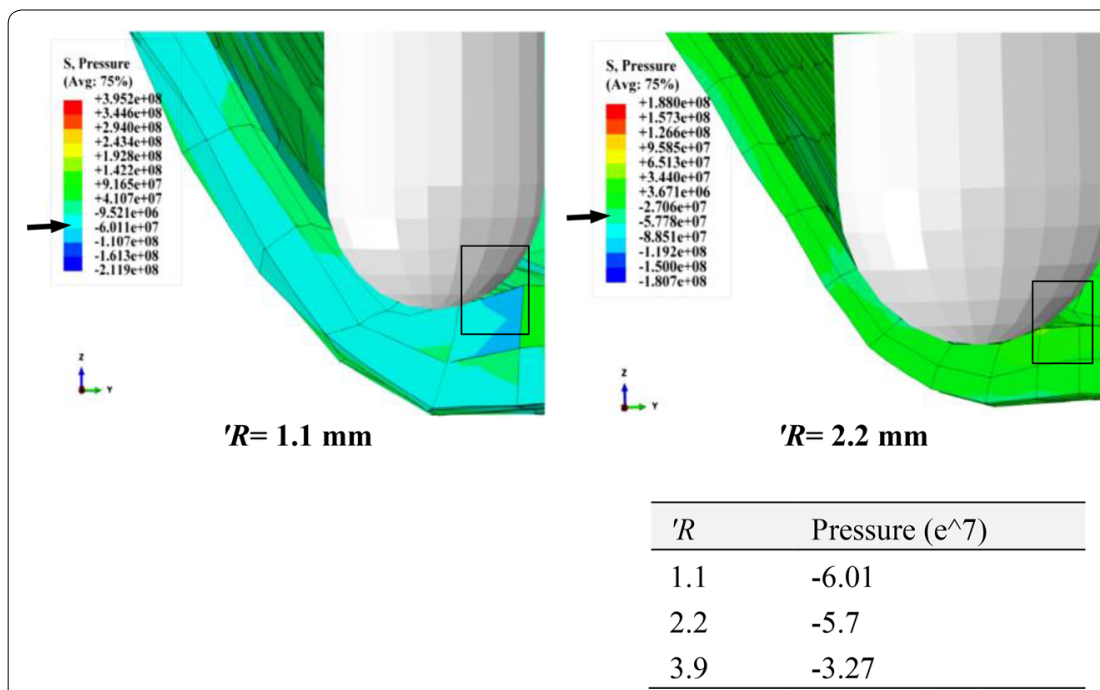

Figure 5 Pressure contours for three levels of normalized tool-radius

profiles at two different levels of part depth (i.e., $5 \mathrm{~mm}$ and $20 \mathrm{~mm}$ ) in Figure 6(b) and (c). This scenario subsequently causes premature failure and formability reduction. Therefore, such a condition should be avoided in SPIF by choosing a suitable tool-radius.

\section{Discussion}

The experimental and analytical studies in the literature have reported that the formability in SPIF generally shows a downward trend when the tool-radius is increased, because the damage (i.e., volume of voids) and hydrostatic tension increase or in other words the hydrostatic compression decreases [21-24]. The present study, on the contrary, shows that the formability reduces even with the decreasing of tool-radius if the radius is below a critical value of ' $R_{c}$ (i.e., left side of formability curve). Analyzing formability in the pressing process, Kweon et al. [29] have reported that compression under the punch reduces damage; however, too large compression could lead severe damage and premature sheet fracturing. Combining the in-plane compression, metal plowing and reduced formability with ' $R_{c}<2.2-3.3$ dictates that the in-plane compression leads to sever damage in SPIF. Achievement of the highest formability against the critical small radius ' $R_{c}$ (radius that does not cause plowing) indicates that a little shear is useful for enhancing the formability in SPIF. This finding is in good agreement with Ref. [15] in which it has been reported that shear improves the formability. The current study clarifies that excessive shear, however, is not conducive for maximizing the formability.

In order to know the effect of using unduly small tools on forming of the shallow parts (i.e., forming at low angles), a $20^{\circ}$ cone was formed employing a tool of 1.2 mm radius and $1 \mathrm{~mm}$ thick sheet (i.e., $R<{ }^{\prime} R_{c}$ ) of AA1060O. Contrary to steep forming (i.e., $55^{\circ}$ angle cone), material squeezing was not so severe. However, the center of blank was observed to bulge out in the form of a pillow, which occurs due to in-plane biaxial compression, bending moment and thickening of material around the forming tool [30]. Due to increase in the pillow height with forming depth, consequently the sheet metal ruptured at the tool/sheet interface (see Figure 7). For AA1060-O, the formability window was found to be between $25^{\circ}$ and $76^{\circ}$. This follows that the use of unduly small tools does not only reduce the process window on the higher side but also on the lower side of forming angle.

Summarizing the present findings, the radius of forming tool affects the strain/pressure state in SPIF. Further, the critical small radius (i.e., ' $R_{c}$ ) offering the maximum formability is almost independent of step size. However, the condition of material has a certain effect on this radius. The value of ' $R_{c}$ increases as the sheet thickness increases (i.e., from 2.2 to 3.3 as the thickness increases from $1 \mathrm{~mm}$ to $3 \mathrm{~mm}$ ). The formability regardless of the forming parameters demonstrates an inverse V-type trend. Moreover, forming with tools corresponding to left side of the V-curve does not narrow the process window only on the upper side but also on the lower side.

\section{Conclusions}

In the current work, the formability characterization in SPIF was carried out employing small tools. The formability tests were performed employing a range of sheet thicknesses, various materials and step sizes, and a 

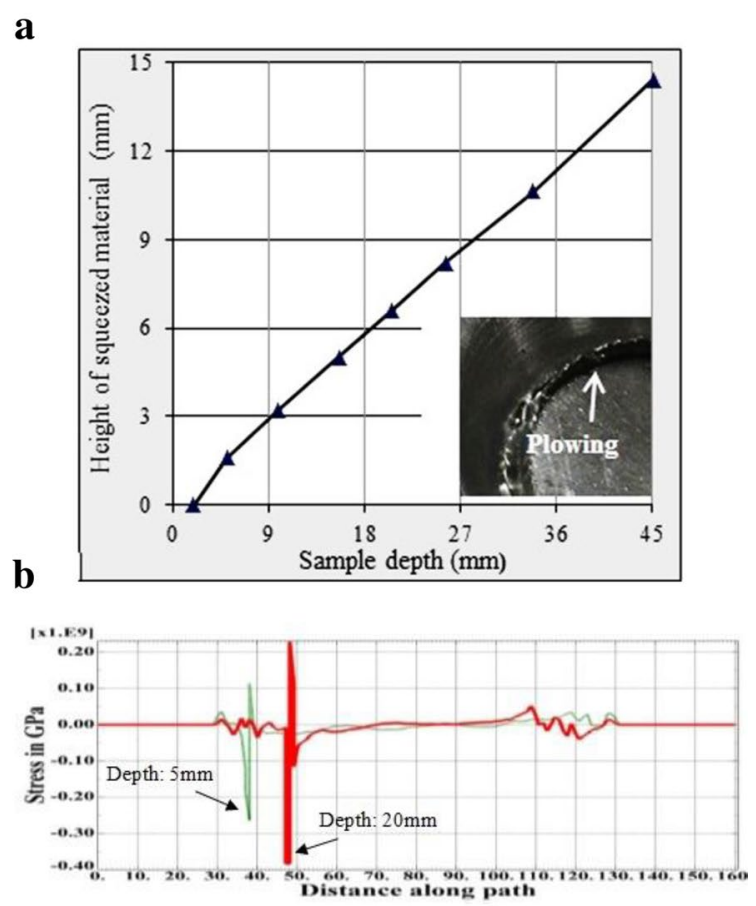

C

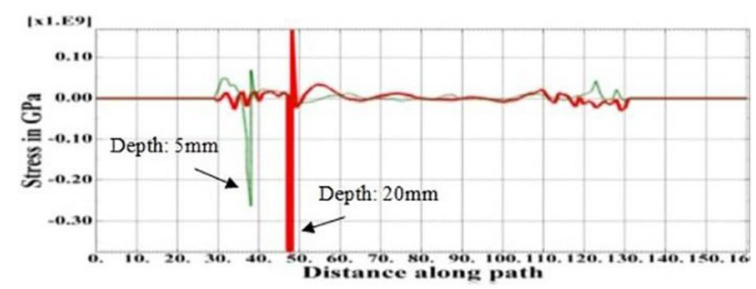

Figure 6 Selected results for a sample formed with the tool-radius of $1.1 \mathrm{~mm}$ : (a) Progression of squeezed material; (b) $X$ - stress for two depths of sample; and (b) Y-stress for two depths of sample

new level of understanding on the critical small radius in SPIF was attained. The following are the important findings:

1. There is a critical radius $R_{c}$ that maximizes the formability in SPIF. Its value depends on the thickness of sheet such that $R_{c}=\beta T_{\mathrm{o}}$ where the coefficient $\beta$ ranges from 2.2 to 3.3 as the thickness increases from $1 \mathrm{~mm}$ to $3 \mathrm{~mm}$. Further, its value is independent of step size in the investigated range. This newly proposed condition can facilitate the users to maximize the formability without doing trial and error tests for a wider range of forming conditions.

2. The selection of tool with $R<R_{c}$ does not only reduce the high limit of formability but also diminishes the low limit thereby narrowing down the overall pro-

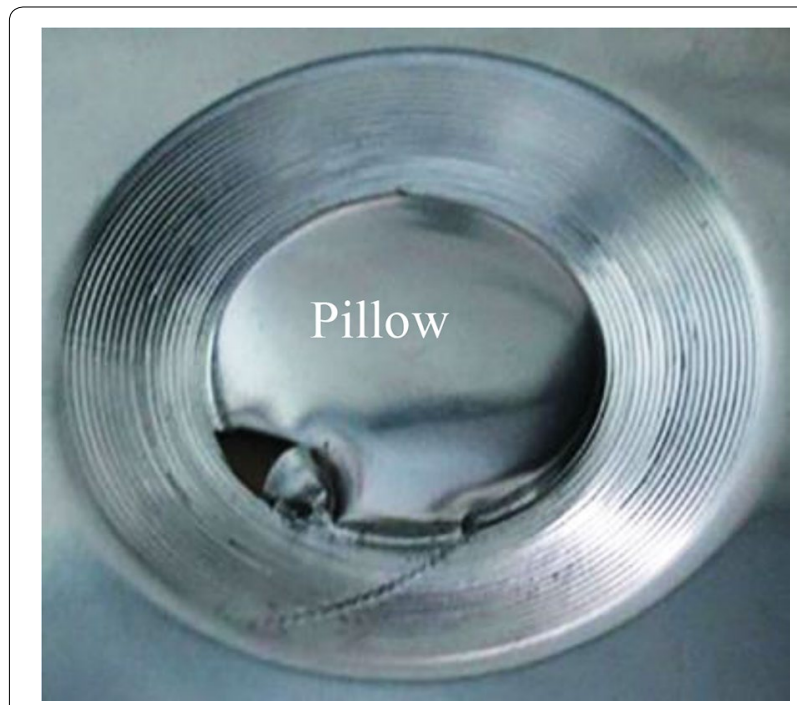

Figure 7 Rupturing of sheet material due to pillowing during forming a shallow part using an unduly small tool (' $R=1.1 \mathrm{~mm}$ )

cess window of SPIF. As instance, the formability window was observed to reduce between $25^{\circ}$ and $76^{\circ}$ when AA1060-O sheet was processed with the tool of radius of $1.2 \mathrm{~mm}$. The higher limit decreases due to undue shearing and stretching, and lower limit reduces due to pillowing of sheet metal.

3. Bi-axial in-plane compression on the inner side of sheet imparts non-conducive condition to maximize the formability. Moreover, this occurs only when the selected radius of forming tool is smaller than the critical one (i.e., for $R<R_{c}$ ).

4. Regardless of the forming parameters, the formability as a function of tool-radius follows an inverse V-type trend. Therefore, V-curve is a characteristic of formability in SPIF.

\section{Abbreviations}

SPIF: Single Point Incremental Forming; $R$ : Tool-radius; $T_{0}$ : Sheet thickness; $R$ : Ratio of tool-radius and sheet thickness; $R_{c}$ : Critical tool-radius maximizing the formability; $\theta_{\max }$ : Maximum value of angle without sheet fracturing; ' $\theta_{\max }$ ' Maximum value of achievable $\theta_{\text {maxi }} F E A$ : Finite element analysis.

\section{Acknowledgements}

The authors are thankful to the GIK Institute, and Nanjing University of Aeronautics \& Astronautics for providing technical assistance and resources to complete this research study. The authors also extend their appreciation to the Deanship of Scientific Research at King Saud University for funding this work through research group number RG-1439-027.

\section{Authors' Contributions}

HW and GH prepared the plan and executed the experiments. XS and BBLI conducted FEA study. MA and MHA arranged sheet materials, and performed critical analyses leading to conclusions and participated in the manuscript writing. All authors read and approved the final manuscript. 


\section{Authors' Informations}

Hongyu Wei, born in 1979, is currently Associate Professor at Nanjing University of Aeronautics \& Astronautics, China. He received his PHD degree from Nanjing University of Aeronautics \& Astronautics, China, in 2011. His research interests include materials and manufacturing.

G Hussain, born in 1977, is currently Professor at GIK Institute of Engineering Sciences \& Technology, Pakistan. He received his PHD degree from Nanjing University of Aeronautics \& Astronautics, China, in 2009. His research interests include materials processing and advanced manufacturing processes.

X Shi, born in 1985, is currently Associate Professor at Shanghai University of Engineering Science, China. He received his PHD degree from Nanjing University of Aeronautics \& Astronautics, China, in 2010. His research interests include advanced manufacturing processes.

BBL Isidore, born in 1990, is currently a PHD candidate at Bradenburg University of Technology, Germany. His research interests include incremental forming and flanging.

Mohammed Alkahtani, born in 1978, is currently Associate Professor at King Saud University, Saudi Arabia. He received his PHD degree from Loughborough University, UK, in 2013. His research interests include manufacturing and supply chain management.

Mustufa Haider Abidi, born in 1986, is currently Researcher at Advanced Manufacturing Institute, King Saud University, Saudi Arabia. He received his Master's degree from King Saud University, Saudi Arabia, in 2012. His main research interests include forming and welding processes.

\section{Funding}

Supported by Fundamental Research Funds for the Central Universities [Grant No. NS2015055 and No. NP2020413]; and High-End Foreign Experts Project with Universities Directly under the Administration of Ministries and Commissions of the Central Government [Grant No. 011951G19061]; and National Natural Science Foundation of China [Grant No. 51105202]. The authors also extend their appreciation to the Deanship of Scientific Research at King Saud University for funding this work through research group number RG-1439-027.

\section{Availability of Data and Materials}

The data supporting the conclusions is reported in this manuscript. Therefore, any additional data is not required to be attached.

\section{Competing Interests}

The author(s) declare(s) that they have no competing interests.

\section{Author Details}

${ }^{1}$ College Mechanical \& Electrical Engineering, Nanjing University of Aeronautics \& Astronautics, Nanjing, People's Republic of China. ${ }^{2}$ Faculty of Mechanical Engineering, GIK Institute of Engineering Sciences \& Technology, Topi 23460, Pakistan. ${ }^{3}$ College of Mechanical Engineering, Shanghai University of Engineering Science, Shanghai, People's Republic of China. ${ }^{4}$ Bradenburg University of Technology, Cottbus, Germany. ${ }^{5}$ Industrial Engineering Department, College of Engineering, King Saud University, Riyadh 11421, Saudi Arabia. ${ }^{6}$ Advanced Manufacturing Institute, King Saud University, Riyadh 11421, Saudi Arabia.

Received: 12 July 2018 Revised: 19 June 2020 Accepted: 28 July 2020 Published online: 18 August 2020

\section{References}

[1] H Wang, F Ye, L Chen, et al. Sheet metal forming optimization by using surrogating modeling techniques. Chinese Journal of Mechanical Engineering, 2017, 30(1): 22-36.

[2] SBM Echrif, M Hrairi. Research and progress in incremental sheet forming processes. Materials \& Manufacturing Processes, 2011, 26(11): 1404-1414.

[3] J Jeswiet, F Micari, G Hirt, et al. Asymmetric single point incremental forming of sheet metal. CIRP Annals, 2005, 54(2): 88-114.
[4] L Lei, W Zhou, G Hussain. Prediction of single point incremental forming limit. Chinese Journal of Mechanical Engineering, 2010, 46(18): 102-107.

[5] G Ambrogio, L Filice, F Gagliardi. Improving industrial suitability of incremental sheet forming process. International Journal of Advanced Manufacturing Technology, 2012, 58(9-12): 941-947.

[6] G-J Dong, C.C Zhao, M. Y Cao. Flexible-die forming process with solid granule medium on sheet metal. Transactions of Nonferrous Metals Society of China, 2013, 23 (9): 2666-2677.

[7] KA Al-Ghamdi, G Hussain. The pillowing tendency of materials in incremental forming: Experimental and FE analyses. Proceedings of the Institution of Mechanical Engineers Part B: Journal of Engineering Manufacture, 2015, 229(5): $744-753$

[8] J-C Li, C Li, T Zhou. Thickness distribution and mechanical property of sheet metal incremental forming based on numerical simulation. Transaction of Nonferrous Metals Society of China, 2012, 22(1): s54-s60.

[9] G Fan, L Gao, G Hussain, et al. Electric hot incremental forming: A novel technique. International Journal of Machine Tools and Manufacture, 2008, 48(15): 1688-1692.

[10] F Han, J. H Mo, H Qi, et al. Springback prediction for incremental sheet forming based on FEM-PSONN technology. Transactions of Nonferrous Metals Society of China, 2013, 23 (4): 1061-1071.

[11] X Shi, G Hussain, G Zha, et al. Study on formability of vertical parts formed by multi-stage incremental forming. International Journal of Advanced Manufacturing Technology, 2014, 75(5-8): 1049-1053.

[12] M S Shim, J J Park. The formability of aluminum sheet in incremental forming. Journal of Materials Processing Technology, 2001, 113(1-3): 654-658.

[13] L Fratini, G Ambrogio, R D Lorenzo, et al. Influence of mechanical properties of the sheet material on formability in single point incremental forming. CIRP Annals, 2004, 53(1): 207-210.

[14] G Hussain, L Gao, N Hayat. Empirical modelling of the influence of operating parameters on the spifability of a titanium sheet using response surface methodology. Proceedings of the Institution of Mechanical Engineers Part B: Journal of Engineering Manufacture, 2009, 223(1): 73-81.

[15] Kathryn Jackson, Julian Allwood. The mechanics of incremental sheet forming. Journal of Materials Processing Technology, 2009, 209(3): 1158-1174.

[16] A Hadoush, AH Van Den Boogaard, WC Emmens. A numerical investigation of the continuous bending under tension test. Journal of Materials Processing Technology, 2011, 211(12):1948-1956.

[17] M B Silva, P S Nielsen, N Bay, et al. Failure mechanisms in single point incremental forming of metals. International Journal of Advanced Manufacturing Technology, 2011, 56: 893-903.

[18] G Centeno, I Bagudanch, AJ Martinez-Donaire, et al. Critical analysis of necking and fracture limit strains and forming forces in single-point incremental forming. Materials and Design, 2014, 63(21): 20-29.

[19] L Filice, L Fratini, F Micari. Analysis of material formability in incremental forming. CIRP Annals, 2002, 51(1): 199- 202.

[20] M Hama, J Jeswieta. Single point incremental forming and forming criteria for AA3003. CIRP Annals, 2006, 55(1): 241-248.

[21] G Hirt, J Ames, M Bambach, et al. Forming strategies and process modelling for CNC incremental sheet forming. CIRP Annals, 2004, 53(1): 203-206.

[22] M B Silva, M Skjoedt, P.A.F. Martins, et al. Revisiting the fundamentals of single point incremental forming by means of membrane analysis. International Journal of Machine Tools and Manufacture, 2007, 48(1): 73-83.

[23] M B Silva, M Skjoedt, A G Atkins, et al. Single point incremental forming and formability-failure diagrams. Journal of Strain Analysis for Engineering Design, 2008, 43(1): 15-35.

[24] Y Fang, B Lu, J Chen, et al. Analytical and experimental investigations on deformation mechanism and fracture behavior in single point incremental forming. Journal of Materials Processing Technology, 2014, 214(8): 1503-1515.

[25] KA Al-Ghamdi, G Hussain. Threshold tool-radius condition maximizing the formability in SPIF considering a variety of materials: experimental and FE investigations. International Journal of Machine Tools and Manufacture, 2015, 88: 82-94.

[26] G Hussain, L Gao. A novel method to test the thinning limits of sheetmetals in negative incremental forming. International Journal of Machine Tools and Manufacture, 2007, 47(3-4) 419-435. 
[27] G Hussain, L Gao, N Hayat, et al. On the effect of curvature radius on the spifability. Advanced Materials Research, 2010, 129-131: 1222-1227.

[28] P Eyckens, B Belkassem, C Henrard, et al. Strain evolution in the single point incremental forming process: digital image correlation measurement and finite element prediction. International Journal of Material Forming, 2011, 4(1): 55-71.

[29] S Kweon, A J Beudoin, R J Mcdonald. Experimental characterization of damage processes in aluminum AA2024-O. Journal of Engineering Materials and Technology, 2010, 132(3): 1-9.
[30] G Hussain, KA Al-Ghamdi, H Khalatbari, et al. Forming parameters and forming defects in incremental forming Process: Part B. Materials and Manufacturing Processes, 2014, 29(4): 454-460.

\section{Submit your manuscript to a SpringerOpen ${ }^{\circ}$ journal and benefit from:}

- Convenient online submission

- Rigorous peer review

- Open access: articles freely available online

- High visibility within the field

- Retaining the copyright to your article

Submit your next manuscript at $>$ springeropen.com 